\title{
Poza psychologię głębi - dyskurs biblijny w świetle social-scientific criticism ${ }^{1}$
}

\author{
Beyond Depth Psychology - Biblical Discourse \\ in the Light of Social Scientific Criticism
}

\author{
AMADEUSZ CITLAK \\ Polska Akademia Nauk, Warszawa \\ acitlak@psych.pan.pl \\ ORCID: 0000-0001-6550-1891
}

\begin{abstract}
The article presents the most important trends and achievements of the psychological interpretation of the biblical text in recent years. The main goal, however, is to propose going beyond the quite controversial - though interesting - research from the perspective of depth psychology (Tiefenpsychologie), which completely dominated psychological biblical criticism in the 20th century. Therefore I'll focus on well verified psychological theories (especially social psychology and social cognition) which are widely recognized among psychologists, and which seem to significantly enrich the conceptual apparatus of the contemporary biblical scholar and allow for a better understanding of the social milieu in biblical books. Psychological biblical criticism can be very valuable and useful method in contemporary exegesis, but it have to overcome the limitations of depth psychology.
\end{abstract}

KEYWORDs: psychological biblical criticism, biblical psychology, depth psychology, social psychology, social cognition

SŁOWA KLUCzowe: psychological biblical criticism, psychologia biblijna, psychologia głębi, psychologia społeczna, psychologia poznania społecznego

Dychologiczna interpretacja ksiąg biblijnych od bardzo dawna zajmuje istotne miejsce w biblistyce. Wprawdzie wiąże się ją zazwyczaj z rozwojem psychologii na przełomie XIX i XX w., jednak ten rodzaj podejścia do tekstu biblijnego w mniejszym lub większym stopniu towarzyszył badaczom w zasadzie już od starożytności. Trudno się temu dziwić, skoro wiele zagadnień biblijnych dotyczy bezpośrednio tematyki z obszaru psychologii: przebaczenie, nadzieja, miłość, duch, serce, sumienie itp. Pojęcia te zazwyczaj były (i są) przedmiotem badań z zakresu antropologii biblijnej lub włączano je w szerszą perspektywę soteriologiczną, dzięki czemu uzyskiwały właściwy sobie kontekst i znaczenie. Nie ulega

$1 \quad$ Artykuł przygotowany w ramach grantu Ministerstwa Nauki i Szkolnictwa Wyższego: Doskonała Nauka - Wsparcie Monografii Naukowych: Dyskurs biblijny w świetle psychologii szkoty lwowsko-warszawskiej - DNM/SP/461604/2020. 
wątpliwości, że instrumentarium pojęciowe, jakiego dostarcza współczesna psychologia (szczególnie psychologia społeczna i kulturowa), stwarza nowe możliwości pełniejszego zrozumienia społecznego i egzystencjalnego Sitz im Leben człowieka ukazanego w tradycji biblijnej².

Psychologiczne refleksje nad księgami biblijnymi snuli powszechnie zarówno ojcowie apostolscy, ojcowie Kościoła (np. Augustyn, Tomasz z Akwinu), ojcowie reformacji (np. Filip Melanchton, Jan Kalwin), jak i współcześni bibliści i teolodzy (m.in. Paul Tillich). Zasadnicze zmiany przyniósł jednakże wiek XIX wraz z opublikowaniem rozpraw Franza Delitzscha, System der biblischen Psychologie (1855), Johanna T. Becka Umriss der biblischen Seelenlehre (1877) ${ }^{3}$ i M. Scotta Fletchera The Psychology of the New Testament (1912). Pierwsza z nich stanowi w literaturze przedmiotu coś w rodzaju „otwarcia” lub ,zapoczątkowania" psychologii biblijnej, której zadaniem miało być odtworzenie biblijnego obrazu psychicznego życia człowieka i jego kondycji duchowej w świetle upadku i odkupienia. Z upływem czasu, wraz z rozwojem młodej wówczas i stawiającej pierwsze kroki psychologii naukowej/empirycznej, której narodziny datuje się oficjalnie na rok 1879, związany z otwarciem laboratorium psychologicznego na Uniwersytecie Lipskim przez Wilhelma Wundta, psychologia biblijna stawała w obliczu przeróżnych (często sprzecznych) teorii, pojęć, a nawet szkół psychologicznych. Początek XX w., zdominowany przez behawioryzm i psychoanalizę, sprzyjał psychologicznej refleksji nad narracją biblijną praktycznie wyłącznie w świetle tej drugiej teorii. W tradycji psychologii głębi, stworzonej przez Sigmunda Freuda i jego uczniów, nie tylko bowiem istniała przestrzeń dla tego typu rozważań (inaczej niż w ówczesnym, radykalnym beahawioryzmie), ale co najważniejsze, świat przeżyć religijnych uważano za jeden z istotnych przejawów życia psychicznego człowieka. Chociaż sam Freud traktował religię jako źródło nerwic i problemów psychicznych ${ }^{4}$, to Carl G. Jung widział w niej przestrzeń optymalnego rozwoju ludzkiej psyche, a nawet indywiduacji, której doskonałym przykładem miał być Jezus Chrystus. Religia dla Junga miała być cura animarium, a systemy religijne niczym innym jak systemami terapeutycznymi ${ }^{5}$.

2 M. Czajkowski, Egzystencjalna lektura Biblii (Lublin: Redakcja Wydawnictw KUL 1993) 72-80.

3 Wcześniej pojawiła się również praca Magnusa Friedricha Roosa Fundamenta psychologiae ex sacra Scriptura sic collecta (Tübingen: Fuessi 1769).

4 S. Freud, „Czynności natrętne a praktyki religijne”, S. Freud, Charakter i erotyka (Warszawa: Wydawnictwo KR 1996); Z. Freud, „Totem i Tabu”, Z. Freud, Człowiek, religia, kultura (Warszawa: Książka i Wiedza 1967) 25-146; Z. Freud, „Przyszłość pewnego złudzenia”, Z. Freud, Człowiek, religia, kultura (Warszawa: Książka i Wiedza 1967) 147-199.

5 C.G. Jung, „Odpowiedź Hiobowi”, C.G. Jung, Psychologia a religia Wschodu i Zachodu (tt. R. Reszke) (Warszawa: Wydawnictwo KR 2005) 553-758; C.G. Jung, Archetypy i symbole. Pisma wybrane (tt. J. Prokopiuk) (Warszawa: Czytelnik 1976); C.G. Jung, Archetypy i nieświadomość zbiorowa (tł. R. Reszke) (Warszawa: Wydawnictwo KR 2011). 
Wiek XX - jeśli chodzi o psychologiczną interpretację ksiąg biblijnych - został całkowicie zdominowany przez psychologię głębi w wydaniu teorii Freuda i Junga. Istnieje obecnie niezliczona ilość publikacji, rozpraw, artykułów, wyników badań, których choćby pobieżna prezentacja przekracza możliwości objętościowe tego artykułu. Podjęto już chyba wszelkie możliwe próby odczytania ksiąg świętych w optyce konfliktów sił nieświadomych, kompleksu Edypa, wypartej seksualności czy jungowskich archetypów, nieświadomości zbiorowej, jaźni itd. Z perspektywy czasu trzeba przyznać, że wiele z tych prób było teoretycznymi nadużyciami i przykładami nieuzasadnionego dostosowania tekstu do założeń psychoanalizy i psychologii analitycznej. Wynikało to w dużym stopniu z faktu, iż autorami tych prac byli nie tyle bibliści, co psycholodzy lub badacze bez wrażliwości egzegetycznej. Dość często jawnie abstrahowali oni (by nie powiedzieć - lekceważyli) od warstwy semantycznej tekstu, traktując go jako przepracowaną przez ludzką podświadomość przestrzeń, w której ujawniają się zawoalowane siły i podświadome konflikty (np. nieakceptowane impulsy seksualne). Przykładowo wąż w ogrodzie Eden symbolizował fallusa, a grzech Adama i Ewy dotyczył przekroczenia seksualnego tabu. Sytuacja wygląda o wiele lepiej w przypadku analiz Junga i jego zwolenników, którzy historię biblijną traktowali jako wyraz rozwoju ludzkiej psyche. Jednak ostatecznie także i tutaj treść ksiąg biblijnych została podporządkowana apriorycznie założonym pojęciom lub mechanizmom psychologicznym, niejednokrotnie obcym antropologicznej rzeczywistości Biblii ${ }^{6}$.

Po okresie negacji pierwszych prób tego typu, ostro skrytykowanych przez samych biblistów, w latach 80 . XX w. nastąpił powolny zwrot w kierunku ponownego zainteresowania się analizą psychologiczną. Nie bez znaczenia miały tu prace Eugena Drewermanna ${ }^{7}$, Klausa Bergera ${ }^{8}$, a przede wszystkim głośna praca Gerda Theissena Psychologische Aspekte der paulinischen Theologie (1983), w której autor - na przykładzie listów św. Pawła - przekonująco pokazał, że analiza tekstu biblijnego w świetle psychologii głębi wymaga uzupełnienia jej o nowe teorie i nurty współczesnej psychologii, z których on sam proponował psychologię kognitywną i psychologię uczenia się. Dopiero wówczas taka analiza ma szansę być wiarygodna i wartościowa dla współczesnego biblisty oraz wnieść znaczące treści do całokształtu jego pracy egzegetycznej z danym tek-

6 Y. Spiegel (red.), Psychoanalytische Interpretationen biblischer Texte (München: Kaiser 1972); G. Lohfink - R. Pesch, Tiefenpsychologie und keine Exegese. Eine Auseinandersetzung mit Eugen Drewermann (Stuttgart: Katholisches Bibelwerk 1987) 11-47.

7 E. Drewermann, Strukturen des Bösen. I. Die jahwistische Urgeschichte in psychoanalytischer Sicht (Padeborn: Schöningh 1988); E. Drewermann, Tiefenpsychologie und Exegese (Olten: Walter 1985) I-II; A. Citlak, „Psychologia historyczna tekstu antycznego (biblijnego) - Eugena Drewermanna tiefenpsychologische Auslegung", Interpretacja tekstu antycznego - inspiracje (red. A. Citlak) (Kraków: Libron 2017) 59-76.

$8 \quad$ K. Berger, Historische Psychologie des Neuen Testaments (Stuttgart: Katholisches Bibelwerk 1991). 
stem biblijnym ${ }^{9}$. Dużą zmianę przyniósł również dokument Papieskiej Komisji Biblijnej Interpretacja Pisma Świętego w Kościele (1993) ${ }^{10}$, w którym interpretację psychologiczną zaliczono do tzw. „podejść”, w odróżnieniu od uznanych już „metod” egzegetycznych (wynikało to z braku jednoznacznej metodologii i jednoznacznych procedur badawczych egzegezy psychologicznej). Wprawdzie $\mathrm{w}$ dokumencie tym interpretacja psychologiczna została praktycznie utożsamiona z nurtem psychologii głębi, to jednak autorzy dokumentu wyraźnie doceniają ten rodzaj egzegezy i zachęcają do jego wykorzystania, szczególnie tam, gdzie chodzi o symbolikę języka religijnego lub zastosowania duszpasterskie. Taki jest również status psychological biblical criticism w świetle samej psychologii głębi: może on mieć duże znaczenie terapeutyczno-duszpasterskie ${ }^{11}$ i stanowić wartościowe uzupełnienie egzystencjalnego zastosowania lektury ksiąg świętych w duchu Rudolfa Bultmanna ${ }^{12}$.

By nie omawiać jednak dość dobrze już znanej wśród biblistów psychologii głębi, w dalszej części skupię się na bardzo obiecujących i od pewnego czasu dynamicznie rozwijających się w psychologii i biblistyce trendach, które nie tylko wykraczają daleko poza tradycję freudowską, ale zapewniają też zdecydowanie mniej spekulatywne instrumentarium pojęciowo-metodologiczne. Instrumentarium to wydaje się trafnie opisywać realia społeczne i antropologiczne świata biblijnego, a także rzuca wiele światła na niedoceniane dotąd zmienne o charakterze psychologicznym, które w bezpośredni sposób determinują specyfikę myślenia autorów biblijnych o świecie czy konstruowania ich przekonań etycznych i społecznych.

\section{Psychologia społeczna i dyscypliny pokrewne}

Współczesna psychologia oferuje bardzo zróżnicowany zestaw teorii i metod, które wybiegają daleko poza psychoanalizę. Stwarza to zupełnie nowe możliwości badawcze, a jednocześnie zmusza do dialogu i szerszej dyskusji między

9 G. Theissen, Psychologische Aspekte paulinischer Theologie (Göttingen: Vandenhoeck \& Ruprecht 1983). Zob. też J.H. Ellens - W.G. Rollins (red.). Psychology and the Bible. A New Way to Read the Scriptures (Westport, CT: Praeger 1999-2004) I-IV; W.G. Rollins, Soul and Psyche. The Bible in Psychological Perspective (Minneapolis, MN: Fortress 1999); W.G. Rollins - A.D. Kille (red.), Psychological Insight into the Bible (Grand Rapids, MI - Cambridge: Eerdmanns 2007).

10 Commission biblique pontificale, „L'Interprétation de la Bible dans l'Église”, Bib 74/4 (1993) 451-528 (tł. polskie zob. R. Rubinkiewicz [red.], Interpretacja Biblii w Kościele. Dokument Papieskiej Komisji Biblijnej z komentarzem biblistów polskich [RSB 4; Warszawa: Vocatio 1999]).

11 A. Grün, Bilder von Seelsorge. Biblische Modelle einer therapeutischen Pastoral (Mainz: Grünewald 1991).

12 J. Suchy, „Podejście psychologiczne i psychoanalityczne w egzegezie biblijnej”, CT 66/1 (1996) 55-64. 
przedstawicielami różnych pod-dyscyplin. Wyraźnym znakiem takiego zainteresowania były i są nie tylko nowe publikacje, ale też powstanie czasopism naukowych o zasięgu międzynarodowym, m.in. Journal of Psychology and Theology w 1973 r., Journal of Psychology and Christianity w 1982 r. czy dominującego obecnie Biblical Interpretation: A Journal of Contemporary Aproaches w $1993 \mathrm{r}^{13}$ Współcześnie psychologiczna analiza dyskursu biblijnego ma tak wiele twarzy, jak wiele jest subdyscyplin psychologii. Wspomniany G. Theissen już w 1983 r. zaproponował przy interpretacji tekstów Pawłowych psychologię uczenia się i psychologię poznawczą. Obecnie do subdyscyplin należą również psychologia relacji z obiektem, psychologia osobowości, psychologia rozwojowa, behawioralna czy psychologia społeczna i poznania społecznego ${ }^{14}$. Psychological biblical criticism stanowi niezwykle bogaty dział, w którym wiele problemów dawniej nierozpatrywanych, dzisiaj ujmowanych jest w bardzo interesującej optyce. By nie omawiać wszystkich, skupię się na najbardziej znaczących i w mojej ocenie szczególnie ważnych osiągnięciach, które wydają się cieszyć względnie dużym uznaniem środowiska samych biblistów, mianowicie na psychologii społecznej i dyscyplinach z nią związanych.

Zastosowanie psychologii społecznej w narracjach biblijnych stanowi obecnie część szerszego nurtu badań, który w literaturze anglojęzycznej określany jest jako social-scientific criticism. Obejmuje on szereg dyscyplin naukowych, przede wszystkim antropologię, socjologię i psychologię, wykorzystywanych do opisu rzeczywistości społecznej Starego i Nowego Testamentu ${ }^{15}$. Od lat 80 . XX w. przybierał on systematycznie na sile, głównie wśród badaczy amerykańskich i europejskich, by osiągnąc obecnie postać dwóch silnych tradycji badawczych: biblical social history i wspomniany social-scientific criticism. Nagromadzenie danych na temat biblijnego świata społecznego (relacji społecznych, instytucji, ich przemian) jest obecnie tak duże, że wymaga nowego języka opisu, którego dostarczają empiryczne nauki społeczne o coraz bogatszym zapleczu

13 Pierwsze dwa czasopisma miały do niedawna dość ortodoksyjny/konfesyjny charakter, jednak w ostatnim czasie stanowisko to wydaje się ulegać zmianie (np. Journal of Psychology and Theology przesunęło swój ,aim and scope” w kierunku publikacji zorientowanych bardziej empirycznie).

14 Ellens, Rollins, Psychology and the Bible; Rollins, Soul and Psyche; Rollins - Kille (red.), Psychological Insight into the Bible; G. Theissen - P. von Gemünden (red.), Erkennen und Erleben. Beiträge zur psychologischen Erforschung des frühen Christentums (Gütersloh: Gütersloher Verlagshaus 2007); G. Theissen (red.), Erleben und Verhalten der ersten Christen. Eine Psychologie des Urchristentums (Gütersloh: Gütersloher Verlagshaus 2007).

15 J.H. Elliott, Conflict, Community, and Honor. 1 Peter in Social-Scientific Perspective (Eugene, OR: Wipf \& Stock 2007); J. Pilch (red.), Social Scientific Models for Interpreting the Bible. Essays by the Context Group in Honor of Bruce J. Malina (BibInt 53; Leiden: Brill 2001); P.F. Esler, The First Christians in their Social Worlds. Social-scientific Approaches to New Testament Interpretation (New York - London: Routledge 1994); P. Luomanen - I. Pyysiainen - R. Uro (red.), Explaining Early Judaism and Christianity. Contributions from Cognitive and Social Science (Leiden: Brill 2007). 
pojęciowo-metodologicznym. Zwolennicy tego nurtu twierdzą wprost, że taki zabieg jest niezbędny dla właściwego zrozumienia treści Bibliii ${ }^{16}$. W praktyce powinien obejmować najpierw opis rzeczywistości społecznej (,description of the relevant social data"), a następnie próbę jej wyjaśnienia („explanations of social facts") poprzez formułowanie hipotez na temat możliwych powiązań i zależności. Hipotezy te powinny być weryfikowane na podstawie zebranych danych ${ }^{17}$, co miałoby minimalizować dowolność interpretacyjną.

\section{Social identity theory}

Obecnie jedną z najczęściej eksplorowanych teorii w social scientific criticism jest teoria tożsamości społecznej (social identity theory) Henriego Tajfela i Johna C. Turnera, wypracowana w latach 70. i $80 . \mathrm{XX} \mathrm{w.} \cdot{ }^{18} \mathrm{~W}$ świetle jej założeń jednym z podstawowych dążeń człowieka jest potrzeba pozytywnego wizerunku i samooceny, uzyskiwanych przede wszystkim na drodze identyfikacji grupowych. Tożsamość społeczna, wynikająca z takich identyfikacji, wiąże się ściśle z podstawowym mechanizmem poznawczym, tj. kategoryzacją ja (włączeniem ja do większej kategorii - my). Sam proces kategoryzacji społecznej jest jednak obarczony błędami i podlega pewnym uproszczeniom, z których najważniejszym jest zjawisko akcentuacji, polegające na akcentowaniu przez umysł różnic międzykategorialnych ( $\mathrm{tj}$. różnic między kategorią my a wy/oni) i podobieństw wewnątrzkategorialnych (on, ona ujednolicani wewnątrz kategorii wy/oni). Proces ten jest niestety tendencyjny, obarczony dążeniem do faworyzacji swoich i defaworyzacji obcych. Swoi wypadają zazwyczaj lepiej w porównaniach z obcymi, którzy z kolei jawią się jako bardziej monolityczna, ujednolicona zbiorowość. Kategoryzacja i akcentuacja prowadzą zazwyczaj do wytworzenia stereotypów zarówno pozytywnych grupy własnej, jak i negatywnych grupy obcej. Są to procesy

16 „Like text criticism, literary criticism, narrative criticism, historical criticism, form criticism, tradition criticism, rhetorical criticism, and the other criticisms of exegesis, Social-Scientific Criticism is an indispensable operation of an interpretive method" (J. Elliott, ,From Social Description to Social-Scientific Criticism. The History of a Society of Biblical Literature Section 1973-2003”, BTB 38 [2008] 29); podobnie D.G. Horrell, „Social Sciences Studying Formative Christian Phenomena: A Creative Movement", Handbook of Early Christianity. Social Science Approaches (red. A. Blasi J. Duhaime - P.A. Turcotte) (Walnut Creek, CA: AltaMira Press 2002) 3-28.

17 Elliott, „From Social Description”, 30.

18 H. Tajfel - M. Billig, ,Social Categorization and Similarity in Intergroup Behavior”, European Journal of Social Psychology 3 (1973) 27-52; H. Tajfel, Social Identity and Intergroup Relations (Cambridge: Cambridge University Press 1982); H. Tajfel, „Stereotypy społeczne i grupy społeczne”, Studia Psychologiczne 20/2 (1982) 5-25; H. Tajfel - J.C. Turner, „The Social Identity Theory of Intergroup Behavior", Psychology of Intergroup Relation (red. W. Austin - S. Worchel) (Monterey, CA: Brooks - Cole 1986) 33-47. 
tak fundamentalne w relacjach społecznych, że Tajfel i jego współpracownicy stwierdzili ich występowanie nie tylko w warunkach eksperymentalnych i realnych relacjach grupowych, ale też w tzw. paradygmacie grupy minimalnej, tzn. w przypadku losowego przydzielenia osób do wyimaginowanych grup ${ }^{19}$. Teorię tożsamości społecznej rozszerzył J.C. Turner w latach 80. XX w. o stworzoną przez siebie teorię kategoryzacji ja (self categorization theory) ${ }^{20}$. Twierdził on, że kategoryzacja ja może zachodzić na trzech różnych poziomach: a) identyfikacji z całą ludzkością - ja jako część wspólnoty ludzkiej, b) identyfikacji z grupą - ja jako część wspólnoty, c) ja jako niepowtarzalny byt. Kategoryzacja ja nie jest procesem stałym, jednorazowym, ale zachodzi dynamicznie, w zależności od dostępności danej kategorii, jak i aktualnych uwarunkowań bądź okoliczności społeczno-kulturowych. Obie teorie bardzo dobrze tłumaczą procesy kształtowania się tożsamości społecznej (także religijnej danej grupy) i dynamikę relacji wewnątrz- i międzygrupowych, w tym wzajemne konflikty czy dążenie do obrony wizerunku i tożsamości wspólnotowej.

\section{Social identity theory a podziały grupowe i nurt kognitywny}

W świetle Starego i Nowego Testamentu, które są świadectwem dziejów i rozwoju tożsamości społeczno-religijnej judaizmu i wczesnego chrześcijaństwa, wartość heurystyczna obu teorii (social identity theory i self categorization theory) wydaje się niezwykle duża, szczególnie gdy weźmiemy pod uwagę fakt, że zarówno wspólnoty izraelskie, jak i wczesnochrześcijańskie powstawały w warunkach stałego dążenia do podtrzymywania własnej tożsamości, a nawet ciągłej walki o jej zachowanie w obliczu przeróżnych zagrożeń zewnętrznych i wewnętrznych. Próby zastosowania social identity theory w interpretacji ksiąg biblijnych pojawiły się więc dość szybko, tym bardziej że - uwzględniając aspekt społeczny/wspólnotowy psychologicznego funkcjonowania Żydów czy chrześcijan - odwołuje się ona do procesów o charakterze wręcz fundamentalnym. Jest to obecnie bardzo obiecujący nurt badań, którego reprezentantami są - co ważne - bibliści ${ }^{21}$. Jednak popularność i użyteczność teorii (Tajfela i Tur-

19 R.J. Brown - H. Tajfel - J.C. Turner, „Minimal Group Situations and Intergroup Discrimination”, European Journal of Social Psychology 10 (1980) 399-414.

20 J.C. Turner, Rediscovering the Social Group. Self-Categorization Theory (New York: Blackwell 1987); J.C, Turner, „Towards a Cognitive Redefinition of the Social Group”, Social Identity and Intergroup Relations (red. H. Tajfel) (Cambridge: Cambridge University Press 1992) 15-39.

21 C.A. Baker, Identity, Memory, and Narrative in Early Christianity. Peter, Paul, and Recategorization in the Book of Acts (Eugene, OR: Pickwick 2011); C.A. Baker, ,,Social Identity Theory and Biblical 
nera) wynika nie tylko z powyższego powodu. Pozwala ona bowiem w spójny sposób wyjaśniać także zachowania społeczne, których celem jest dążenie do podtrzymania odpowiedniego wizerunku grupy własnej i radykalizacja (bądź negatywizacja) poglądów na temat obcych. Innymi słowy, pozwala spójnie opisać i wyjaśniać istotne elementy światopoglądu społecznego, etycznego i religijnego Żydów i chrześcijan. Tak więc wyjaśnia z jednej strony procesy tworzenia lub ochrony tożsamości wspólnot religijnych, $\mathrm{z}$ drugiej - wzajemne konflikty (np. chrześcijanie - Żydzi, chrześcijanie - poganie, Żydzi - poganie ${ }^{22}$. Znaczącym novum jest również wspomniany powyżej (i dyskutowany coraz częściej) problem światopoglądu społecznego zawartego w narracji biblijnej, a szczególnie jego stereotypowość. Zgodnie bowiem z social identity theory zagrożenie tożsamości niezwykle sprzyja podtrzymywaniu stereotypów wroga lub obcego ${ }^{23}$, którym w Starym i Nowym Testamencie są zazwyczaj poganie, niewierni, a nawet swoi uznani za odstępców. Pokazano to dość przekonująco w analizie starotestamentowego wizerunku pogan ${ }^{24}$ czy nowotestamentowego wizerunku niewiernych ${ }^{25}$, a nawet ortodoksyjnych (tj. niechrześcijańskich) Żydów ${ }^{26}$. Problematyka stereotypowości dyskursu biblijnego jest w mojej ocenie jednym z ważniejszych zagadnień współczesnej hermeneutyki, które ma obecnie znaczące implikacje dla ogólnej oceny przesłania i znaczenia narracji biblijnej. Może ona również pełnić rolę pomocniczą w dialogu międzyreligijnym między przedstawicielami judaizmu i chrześcijaństwa, wskazując istotne uwarunkowania wzajemnych antagonizmów czy nietolerancji religijnej ${ }^{27}$.

Interpretation”, BTB 42 (2012) 129-138; M. Cromhout, „Identity Formation in the New Testament”, HvTSt 65/1 (2009) 1-13; B. Holmberg - M. Winninge (red.), Identity formation in the New Testament (Tübingen: Mohr Siebeck 2008).

22 R. Hakola, „Social Identities and Group Phenomena in Second Temple Judaism”, Explaining Christian Origins and Early Judaism. Contributions from Cognitive and Social Science (red. P. Luomanen - I. Pyysiäinen - R. Uro) (Leiden: Brill 2007) 259-276; R. Hakola, „The Burden of Ambiguity: Nicodemus and the Social Identity of the Johannine Christians", NTS 55 (2009) 438-455; R. Nebreda, Christ Identity. A Social-Scientific Reading of Philippians 2,5-11 (Göttingen: Vandenhoeck \& Ruprecht 2011).

23 Do takich konkluzji prowadzi wiele współczesnych teorii psychologicznych, np. terror management theory, nurt badań nad dehumanizacją czy esencjonalnym postrzeganiem kategorii społecznych.

24 W. Brueggemann, „Stereotype and Nuance: The Dynasty of Jehu”, CBQ 70 (2008) 16-28; D. Macpherson, ,The Politics of Preaching the Promised Land for the Canaanites”, Political Theology 10/1 (2009) 71-84.

25 A.J. Batten, „The Letter of Jude and Graeco-Roman Invective”, HvTSt 70/1 (2014) 1-9.

26 R. Hakola, ,Social Identity and a Stereotype in the Making: The Pharisees as Hypocrites in Matt 23”, Identity Formation in the New Testament (red. B. Holmberg - M. Winnige) (WUNT 227; Tübingen: Mohr Siebeck 2008) 123-139; J. Lamp, ,Is Paul Anti-Jewish? Testament of Levi 6 in the Interpretation of 1 Thessalonians 2:13-16", CBQ 65/3 (2003) 408-427.

27 P.F. Esler, ,Intergroup Conflict and Matthew 23: Towards Responsible Historical Interpretation of a Challenging Text”, BTB 45/1 (2015) 38-59; D.A. Kille, „Unconsciously Poisoning the Roots: Psychological Dynamics of the Bible in Jewish/Christian Conflict", Pastoral Psychology 53/4 (2015) 291-301. 
Psychologiczna analiza światopoglądu autorów biblijnych w świetle teorii psychologii społecznej stwarza szczególne możliwości w połączeniu z psycholingwistyką i nurtem poznania społecznego (social cognition), które oferują własne, aczkolwiek użyteczne w tym względzie narzędzia badawcze. Ich wykorzystanie pozwala nie tylko na względnie spójną teoretycznie i metodologicznie analizę dyskursu, ale umożliwia też odniesienie (porównanie) uzyskanych wyników do całej tradycji badań empirycznych i sposobów myślenia o świecie społecznym dzisiaj. W tym nurcie znajdują się ilościowe i jakościowe badania nad językowym obrazem świata, stylami poznawczymi, stereotypami itp. Przykładem tego jest chociażby analiza językowej reprezentacji „obcych” w Nowym Testamencie z wykorzystaniem wskaźników frekwencyjnych, modelu kategorii lingwistycznych Guna R. Semina i Klausa Fiedlera, czy procesów atrybucyjnych $^{28}$. Językowa reprezentacja świata może być badana na wiele różnych sposobów. W tym nurcie mieszczą się zarówno analizy narracji biblijnych, jak i cały nurt badań strukturalnych tekstu, które są zazwyczaj traktowane jako odrębna metoda ${ }^{29}$. Odpowiednia adaptacja modelu strukturalnego ( $\mathrm{z}$ bohaterem, jego wrogami, celem działania, przeszkodami itp.) do założeń np. social identity theory mogłaby znacznie wzbogacić naszą wiedzę o social cognition autorów biblijnych i ich pojmowaniu świata społecznego. Obiecujące wydaje się także włączenie do psychological biblical criticism osiągnięć narracyjnej psychologii społecznej, a wraz z nią analizy treści kategorialnych (categorial content analysis $)^{30}$, która pozostaje blisko bogatej tradycji badań lingwistyczno-kulturowych na temat słów-kluczy i kategorii organizujących przestrzeń mentalną użytkowników danego języka ${ }^{31}$. Warto tu nadmienić, że analiza kategorialna słów-kluczy czy pól semantycznych stanowi od wieków niejako serce rozważań nad księgami biblijnymi. Już starożytni rabini i wczesnochrześcijańscy pisarze dokonywali szczegółowych zestawień pojęciowo-terminologicznych dla centralnych tematów Starego lub Nowego Testamentu, zaś obecnie badanie pól semantycznych opiera się na drobiazgowej egzegezie, osiągnięciach filologii klasycznej, a nawet

28 A. Citlak, „Problem nadróżnicowania językowego w dokumentach historycznych”, Studia Psychologiczne 52/2 (2014) 40-56; A. Citlak, „O możliwościach psychologicznej analizy tekstów antycznych (Żydzi i chrześcijanie w ilościowej analizie ewangelii)", Meander 70 (2015) 79-96; A. Citlak, „Linguistic Image of the Non-Christian Jews in Early Christian Narratives as a Function of Inter-Group Conflict", Studia Religiologica 52/2-3 (2019) 165-176, 251-264.

29 R. Bartnicki - K. Kłosek, Metody interpretacji Nowego Testamentu (Kraków: Petrus 2014) 78-89, 203-242.

30 J. László et al., „Narrative Language as an Expression of Individual and Group Identity: The Narrative Categorical Content Analysis”, Sage Open 3 (2013) 1-12; J. Liu - J. László, „A Narrative Theory of History and Identity: Social Identity, Social Representations, Society and the Individual", Social Representations and Identity. Content, Process, and Power (red. G. Moloney - I. Walker) (London: Palgrave Macmillan 2007) 85-107.

31 A. Wierzbicka, Słowa-klucze. Różne języki - różne kultury (Warszawa: Wydawnictwo Uniwersytetu Warszawskiego 2007). 
ustaleniach hermeneutyki filozoficznej. Współczesne słowniki biblijne to nic innego jak zestawienie wyników wieloletnich analiz poszczególnych słów, ich sieci semantycznych, etymologii, kontekstów itp. Jednak włączenie tej tradycji do nurtu social cognition i badań nad językową reprezentacją przekonań społecznych lub etycznych stwarza realną szansę dotarcia do świata przeżyć psychicznych autorów ksiąg świętych (co ma bezpośrednie znaczenie dla pracy egzegetycznej biblisty) i odniesienia go do szerszego kontekstu w postaci empirycznie zweryfikowanej współczesnej wiedzy psychologicznej (co z kolei ma istotne znaczenie dla pracy duszpasterskiej).

W ostatnich latach bardzo cennych wyników dostarczyły też analizy tekstu biblijnego w świetle cognitive science, a szczególnie cognitive science of religion. Wynika to po części z wcześniejszych badań, prowadzonych w paradygmacie teorii tożsamości społecznej, której istotnym elementem jest aspekt poznawczy, ale też z dostrzeganej coraz wyraźniej przez religioznawców i biblistów heurystycznej wartości tej nowej dyscypliny ${ }^{32}$. Założenia i osiągnięcia cognitive science pozwalają podjąć merytoryczną dyskusję nad tak poważnymi zagadnieniami, jak specyfika przekonań religijnych, obraz Boga, światopogląd religijny, mentalność, ich ewolucja czy związki z warunkami społeczno-kulturowymi ${ }^{33}$. Zwolennicy tej orientacji prezentują wartościowe instrumentarium pojęciowe, jak też wyniki interdyscyplinarnych badań z zakresu antropologii, lingwistyki, historii i psychologii. Stwarza to szansę badań interdyscyplinarnych, zwłaszcza jeśli chodzi o społeczne uwarunkowania gatunków literackich (Sitz im Leben i die Formgeschichte) lub oddziaływanie tradycji (die Wirkungsgeschichte). Wiele zagadnień organizujących dyskurs biblijny może być z powodzeniem ujętych w nowej optyce i uzyskać odpowiednie miejsce w badaniach nad religią $\mathrm{w}$ ogóle. Jedną z ciekawszych propozycji heurystycznych wydaje się np. teoria umysłu, tj. nabyta ewolucyjnie zdolność do dostrzegania i rozumienia motywacji, celów lub działań drugiego człowieka, zdolność do wyjścia poza własną perspektywę poznawczą i przyjęcia perspektywy innego. Badania nad teorią umysłu pokazały, iż podlega ona zarówno przemianom na drodze ewolucji gatunkowej, jak i rozwoju społeczno-osobniczego ${ }^{34}$. Ma to bezpośrednie przełożenie na związki z rodzajem etyki wspólnotowej, rytuału, poczuciem wspólnoty, wyznaczaniem podziału na swoich i obcych, znaczeniem empatii i emocji

32 T. Tremlin, Minds and Gods. The Cognitive Foundations of Religion (Oxford: Oxford University Press 2010); Theissen - von Gemünden, Erkennen und Erleben.

33 Tremlin, Minds and Gods; czy też próba kognitywnej interpretacji pojawienia się monoteizmu biblijnego: J. Blachowicz, „Monotheism and the Spirituality of Reason”, Zygon 37/2 (2002) 511-529.

34 K. Gray - L. Young - A. Waytz, „Mind Perception Is the Essence of Morality”, Psychological Inquiry 23/2 (2012) 101-124; J.M. Bering, „The Existential Theory of Mind”, Review of General Psychology 6 (2002) 3-24. 
grupowych (funkcji gniewu, obrzydzenia, miłości itd.) ${ }^{35}$. Równie obiecującym obszarem badań jest analiza wielkich postaci biblijnych w perspektywie teorii kognitywnych, które w porównaniu do interpretacji psychoanalitycznych, wydają się zdecydowanie mniej spekulatywne ${ }^{36}$ i pozwalają weryfikować twierdzenia dotyczące czyichś przekonań czy sposobów myślenia na płaszczyźnie języka bądź tekstu. Krótko mówiąc, w perspektywie kognitywnej można na nowo odczytać fundamentalne zagadnienia rzeczywistości religijnej, pod warunkiem, że badacz dysponuje odpowiednim zapleczem empirycznym (materialnym, behawioralnym, językowym, tekstowym) ${ }^{37}$.

\section{Psychologiczne wymiary kultury}

Psychologiczna analiza dyskursu biblijnego boryka się właściwie od samego początku z problemem adekwatności teorii, które powstawały zazwyczaj w XX i XXI w. w kulturze Zachodu. Jest to w zasadzie problem podstawowy, którego nie uniknęła psychologia głębi ani późniejsze nurty psychologii. Wprawdzie złudne poczucie „ogólnoświatowej” powszechności i uniwersalności teorii jest obecnie raczej wspomnieniem niż realnym przekonaniem psychologów, to jednak w praktyce badawczej mamy - nie tak wcale rzadko - do czynienia z bezkrytycznym przenoszeniem teorii XX-wiecznej psychologii na antyczny świat semicki. A przecież - co najmniej w założeniu - procedura ich wykorzystania powinna być poprzedzona refleksją nad ich modyfikacją i adaptacją do świata społecznego Biblii. Sitz im Leben tekstu antycznego po prostu zmusza do takich modyfikacji.

Refleksję nad adekwatnością teorii może znacząco ułatwić dynamicznie rozwijający się nurt psychologii międzykulturowej (cross-cultural psychology), której zadaniem jest m.in. empiryczna weryfikacja uniwersalności teorii psychologicznych i identyfikacja zróżnicowania psychologicznego w różnych

35 I. Czachesz, Cognitive Science and the New Testament. A New Approach to Early Christian Research (Oxford: Oxfrod University Press 2017); J. Ketola, „A Cognitive Approach to Ritual Systems in First-Century Judaism", Explaining Early Judaism and Christianity. Contributions from Cognitive and Social Science (red. P. Luomanen - I. Pyysiainen - R. Uro) (Leiden: Brill 2007) 95-114; L. Martin, „The Promise of Cognitive Science for the Study of Early Christianity”, Explaining Early Judaism and Christianity. Contributions from Cognitive and Social Science (red. P. Luomanen - I. Pyysiainen - R. Uro) (Leiden: Brill 2007) 35-56.

36 Por. np. P.N. Anderson, „The Origin and Development of the Johannine Egō Eimi Sayings in Cognitive-Critical Perspective", Journal for the Study of the Historical Jesus 9 (2011) 139-206; H. Wolff, Jesus der Mann. Die Gestalt Jesu in tiefenpsychologischer Sicht (Stuttgart: Radius 1984).

37 M. Heyden, ,Religious Cognition as Social Cognition”, Studia Religiologica 48/4 (2015) 301-312; M.J. Rossano, „The Religious Mind and the Evolution of Religion”, Review of General Psychology 10/4 (2006) 346-364. 
kulturach świata. Pokazano tu wielokrotnie, że nawet bardzo popularne i - jak sądzono - obowiązujące wszystkich ludzi na świecie teorie są mocno ograniczone geograficznie, a nawet czasowo ${ }^{38}$. Co więcej, w wyniku rozległych badań międzykulturowych udało się wskazać pewne uniwersalne zmienne warunkujące specyfikę psychologiczną przedstawicieli poszczególnych kultur i grup etnicznych czy narodowych. Na przykład gloryfikowana przez lata uniwersalna predykcyjna wartość teorii dysonansu poznawczego okazała się zdecydowanie mniejsza w tzw. społeczeństwach kolektywistycznych niż indywidualistycznych, w których tę teorię stworzono. Nie ma tu miejsca na opis osiągnięć cross-cultural psychology, jednak niektóre z nich, po odpowiedniej adaptacji, mogłyby okazać się niezwykle przydatne dla psychological biblical criticism, np. psychologiczne wymiary kultury Geerta Hofstede'a lub mapa wartości kulturowych Shaloma H. Schwartza.

Użyteczność heurystyczna mapy wartości S.H. Schwartza ${ }^{39}$ dla badacza dyskursu biblijnego (i antycznego w ogóle) wynika z faktu, iż wskazuje ona takie wartości, które odgrywają rolę dominującą i organizującą psychologiczne funkcjonowanie ludzi w różnych kulturach świata. Schwartz wyróżnił najpierw wartości jednostkowe, a potem kulturowe: zakorzenienie (szacunek, posłuszeństwo, rodzina, tradycja, pobożność, grzeczność itp.), hierarchię (skromność, władza, siła, bogactwo), mistrzostwo (zdolność, ambicja, sukces, wpływ, niezależność), autonomię afektywną i intelektualną (przyjemność, radość życia, ekscytujące życie/wolność, ciekawość, twórczość), egalitaryzm (równość, sprawiedliwość, uczciwość, lojalność) i harmonię (jedność z naturą, pokój światowy, ochrona środowiska $)^{40}$. Nie trzeba specjalnie dowodzić, że nawet ogólna identyfikacja tych wartości w dyskursie biblijnym mogłaby znacząco pomóc w ocenie zasad-

P. Boski, Kulturowe ramy zachowań społecznych (Warszawa: Academica - PWN 2009); D.R. Matsumoto - L. Juang, Psychologia międzykulturowa (Gdańsk: GWP 2007); R. Nisbett, Geografia myślenia (Sopot: Smak Słowa 2009).

39 Shaloma H. Schwartz i współpracownicy przebadali ponad 75 tysięcy osób w 60 krajach świata, dzięki czemu opracowano najpierw układ wartości na poziomie indywidualnym, następnie społecznym, a dopiero potem kulturową mapę świata z rozmieszczeniem na niej poszczególnych krajów. Kulturowa mapa wartości obejmuje wartości z poziomu jednostkowego i społecznego, tworząc odrębne wymiary mapy kulturowej świata. Zob. S. Schwartz-L. Sagiv, ,Identifying Cultures Specifics in the Content and Structure of Values", Journal of Cross-Cultural Psychology 26/1 (1995) 92-116; S. Schwartz, ,A Theory of Cultural Values and Some Implications for Work”, Applied Psychology 48/1 (1999) 23-47.

40 Niektóre wartości z poziomu jednostkowego korelują w bardzo specyficzny sposób „z judaizmem, islamem i chrześcijaństwem, aczkolwiek dotyczy to wyznawców tych religii w XX w. Wszystkie trzy religie monoteistyczne najsłabiej korelują z wartościami hedonizmu, podmiotowością i poszukiwaniem doznań, przy czym jedynie islam nieznacznie akceptuje tę ostatnią (...). Natomiast wyraźnie pozytywna korelacja (dla wszystkich religii) zachodzi z tradycjonalizmem, konformizmem, bezpieczeństwem i dobrocią" (A. Citlak, Relacje spoleczne świata antycznego w świetle teorii kratyzmu. Psychologia historyczno-kulturowa w szkole lwowsko-warszawskiej [Warszawa: Instytut Psychologii PAN 2016] 138). 
ności wykorzystania wybranych teorii psychologicznych w pracy egzegetycznej. Na przykład wydaje się, że świat autorów biblijnych znajdował się dość blisko wartości zakorzenienia i hierarchii, zaś przesłanie proroków starotestamentowych i wczesne chrześcijaństwo - blisko egalitaryzmu i harmonii. Ustalenia Schwartza (i generalnie cross-cultural psychology) stawiają zarazem pod znakiem zapytania użyteczność wykorzystania takich teorii, które są zorientowane indywidualistycznie i wyjaśniają zmienność psychologiczną wyłącznie lub głównie w świetle procesów jednostkowych (mniej zaś społecznych), które w przypadku tradycji biblijnej są zazwyczaj podporządkowane procesom grupowym.

Równie pomocne mogłyby okazać się wspomniane wcześniej wymiary kulturowe G. Hofstede ${ }^{41}$ (a przynajmniej część z nich), który zalicza do nich kolektywizm $v s$ indywidualizm, dystans władzy, orientację czasową, unikanie niepewności, męskość vs kobiecość. Nie ma potrzeby referować ich tutaj szczegółowo, warto jedynie nadmienić, że semicki świat biblijny ponad wszelką wątpliwość stanowi przykład kultury kolektywistycznej z całym spektrum związanych z tym cech funkcjonowania psychicznego jej przedstawicieli. W kulturze kolektywistycznej liczy się nade wszystko dobro wspólnoty. Wartością nadrzędną jest lojalność i posłuszeństwo, a dążenia własne schodzą na plan dalszy, ustępując celom ogółu. Wspólnota stanowi niejako całe życie psychiczne jednostki, oferując jej wsparcie i ochronę, co niezwykle sprzyja budowaniu trwałych więzi i poczuciu przynależności. Kolektywizm wyznacza jednocześnie etykę kolektywną, gdzie dobrem jest przede wszystkim społeczność i to, co służy jej przetrwaniu ${ }^{42}$. Kolektywizm determinuje też pojęcie ja ${ }^{43}$ - jest ono immanentnie związane z przestrzenią społeczną tworzoną przez swoich i jednoznacznie odcięte od obcych. Jest to tzw. ja współzależne, relacyjne, które zazwyczaj nie istnieje poza wspólnotą. Dla jednostki najważniejsze są relacje z innymi, a także emocje, które te relacje wzmacniają (szacunek, uwielbienie, braterstwo, posłuszeństwo). Jednym z najważniejszych celów życiowych staje się odnalezienie właściwego miejsca we wspólnocie i uzyskanie jej akceptacji, zaś największą porażką - poczucie odrzucenia i potępienia. Inną cechą kultury kolektywnej jest zazwyczaj gerontokracja. Starsi cieszą się wówczas nie tylko dużym uznaniem i pozycją w grupie, ale też sprawują w niej realną władzę. Wszystkich członków społeczności obowiązuje szacunek dla starszych i tradycji ojców ${ }^{44}$.

41 Podobnie jak w przypadku S. Schwartza, były to wieloletnie i wielokulturowe badania, których wyniki poddawano kolejnej recepcji. Zob. G. Hofstede, Culture's Consequences. Comparing Values, Behaviors, Institutions and Organizations across Nations (Thousand Oakes, CA: Sage 2001); por. Boski, Kulturowe ramy, 90-161.

42 H. Triandis, Individualism and Collectivism (Boulder, CO: Westview Press 1995).

43 H.R. Markus - Sh. Kitayama, „Culture and the Self: Implications for Cognition, Emotion, and Motivation”, Psychological Review 98/2 (1991) 224-253.

44 Wyjątkiem są jednak starotestamentowi prorocy, którzy zakwestionowali ideę odpowiedzialności zbiorowej. 
Pojęcie kolektywizmu ma istotne znaczenie w próbach identyfikacji podstawowej psychologicznej charakterystyki semickiego świata biblijnego, a w powiązaniu z innymi wymiarami kultury, o jakich mówią przedstawiciele cross-cultural psychology, mogłoby dostarczyć użytecznego narzędzia do badania zarówno konkretnych cech mentalności, jak i specyfiki relacji społecznych antycznego judaizmu czy chrześcijaństwa. Współczesne pytania o możliwość zastosowania wybranych teorii psychologicznych w analizie biblijnego dyskursu należałoby więc nawet poprzedzić wstępną oceną wymiarów i wartości kulturowych, w jakich ten dyskurs powstawał. Często bowiem jest tak, że badacz jedynie intuicyjnie zakłada, iż np. teoria tożsamości społecznej lub jakieś prawo psychologii poznawczej „pasuje” do realiów świata semickiego, i na tym się kończy. Taka praktyka doprowadziła do dyskredytacji bądź ośmieszenia wielu znaczących praw psychologicznych, które próbowano wykorzystać w analizie dyskursu biblijnego. Teorie psychologiczne mają swoje ograniczenia i mogą być stosowane jedynie w przypadku adekwatności do zakładanych realiów empirycznych ${ }^{45}$. Niestety ten obszar badań, tj. cross-cultural psychology, nie jest jeszcze eksplorowany na gruncie ksiąg biblijnych, choć zainteresowanie nim wydaje się kwestią czasu.

\section{W ramach konkluzji}

Psychologia dyskursu biblijnego - mniej lub bardziej formalnie uprawiana od starożytności - wyrazistą postać uzyskała dopiero na przełomie XIX i XX w. wraz z rozwojem psychologii jako nauki. Pomijając pierwsze próby, których celem była rekonstrukcja biblijnego wizerunku człowieka jako swoistego ideału życia psychicznego, pierwszą znaczącą tradycję badawczą stanowiła przez wiele lat psychologia głębi w formie zaproponowanej przez S. Freuda i C.G. Junga, a potem liczne jej modyfikacje (m.in. Ericha Fromma, E. Drewemanna). Po długich dyskusjach psychologia głębi znalazła swoje miejsce wśród biblistów, czego wyrazem jest dokument Papieskiej Komisji Biblijnej z 1993 r. Dyskusyjność i nadmierna swoboda interpretacyjna, a przede wszystkim niefalsyfikowalna natura wielu tez Tiefenpsychologie, są największym problemem tej tradycji myślowej, mimo jej znaczącego wkładu w zrozumienie natury narracji biblijnych.

Jednak współczesna, dynamicznie rozwijająca się psychologia oferuje zdecydowanie większy zestaw zarówno zweryfikowanych empirycznie teorii, jak i sprawdzonych narzędzi. W przeciwieństwie do psychoanalizy, chodzi o bada-

45 M. Dymkowski, „O uniwersalności teorii psychologii społecznej”, Psychologia Społeczna 2 (2007) 249-261. 
nia z głównego nurtu psychologii, cieszące się z reguły uznaniem świata naukowego i samych psychologów. Wartość empiryczna, eksplanacyjna i predykcyjna tych teorii jest obecnie duża, a ich użyteczność wykazano niejednokrotnie także poza psychologią. Wykorzystanie jej potencjału widać w literaturze światowej od lat 90. XX w. także w badaniach nad Biblią. Dużym zainteresowaniem cieszą się tu dwie tradycje myślowe: social-scientific criticism i cognitive approach. Wprawdzie ich potencjał jest ciągle odkrywany, jednak wiele prac już pozwoliło spojrzeć na stare problemy psychological-biblical criticism w zupełnie nowym świetle. Prace te mogą być traktowane jako znaczące uzupełnienie dotychczasowych badań w ramach szkoły historyczno-krytycznej. W mojej ocenie na osobną uwagę zasługuje również cross-cultural psychology zarówno ze względu na jej zadania (weryfikacja powszechności i uniwersalności teorii psychologicznych), jak i oryginalne osiągnięcia (np. wymiary kultury, pojęcie ja, mapy wartości). Pozwalają one bibliście dokonać trafniejszych wyborów, jeśli chodzi o wytypowanie i zastosowanie odpowiedniej teorii psychologicznej, a także lepiej zrozumieć specyfikę psychologiczną świata biblijnego. Współczesna psychological biblical criticism musi więc wybiegać poza psychologię głębi, korzystając także z wartościowych osiągnięć XXI-wiecznej psychologii empirycznej, bowiem dopiero wtedy - zgodnie z dawną tezą G. Theissena - da nam bardziej wiarygodny wgląd w mentalność autorów Starego i Nowego Testamentu.

\section{Bibliografia}

Anderson, P.N., „The Origin and Development of the Johannine Egō Eimi Sayings in Cognitive-Critical Perspective", Journal for the Study of the Historical Jesus 9 (2011) 139-206.

Baker, C.A., Identity, Memory, and Narrative in Early Christianity. Peter, Paul, and Recategorization in the Book of Acts (Eugene, OR: Pickwick 2011).

Baker, C.A., „Social Identity Theory and Biblical Interpretation”, Biblical Theology Bulletin 42 (2012) 129-138.

Bartnicki, R. - Kłosek, K., Metody interpretacji Nowego Testamentu (Kraków: Petrus 2014).

Batten, A.J., „The Letter of Jude and Graeco-Roman Invective”, Hervormde Teologiese Studies 70/1 (2014) 1-9.

Beck, J.T., Outlines of Biblical Psychology (Edinburgh: Clark 1877).

Berger, K., Historische Psychologie des Neuen Testaments (Stuttgart: Katholisches Bibelwerk 1991). Bering, J.M., „The Existential Theory of Mind”, Review of General Psychology 6 (2002) 3-24.

Blachowicz, J., „Monotheism and the Spirituality of Reason”, Zygon 37/2 (2002) 511-529.

Boski, P., Kulturowe ramy zachowań społecznych (Warszawa: Academica - PWN 2009).

Brown, R.J. - Tajfel, H. - Turner, J.C., „Minimal Group Situations and Intergroup Discrimination”, European Journal of Social Psychology 10 (1980) 399-414.

Brueggemann, W., ,Stereotype and Nuance: The Dynasty of Jehu”, The Catholic Biblical Quarterly 70 (2008) 16-28. 
Citlak, A., „Problem nadróżnicowania językowego w dokumentach historycznych”, Studia Psychologiczne 52/2 (2014) 40-56.

Citlak, A., „O możliwościach psychologicznej analizy tekstów antycznych (Żydzi i chrześcijanie w ilościowej analizie ewangelii)", Meander 70 (2015) 79-96.

Citlak, A., Relacje spoleczne świata antycznego w świetle teorii kratyzmu. Psychologia historyczno-kulturowa w szkole lwowsko-warszawskiej (Warszawa: Instytut Psychologii PAN 2016).

Citlak, A., „Psychologia historyczna tekstu antycznego (biblijnego) - Eugena Drewermanna tiefenpsychologische Auslegung", Interpretacja tekstu antycznego - inspiracje (red. A. Citlak) (Kraków: Libron 2017) 59-76.

Citlak, A., „Linguistic Image of the Non-Christian Jews in Early Christian Narratives as a Function of Inter-Group Conflict”, Studia Religiologica 52/2-3 (2019) 165-176, 251-264.

Commission biblique pontificale, „L'Interprétation de la Bible dans l'Église”, Biblica 74/4 (1993) 451-528.

Cromhout, M., „Identity Formation in the New Testament”, Hervormde Teologiese Studies 65/1 (2009) 1-13.

Czachesz, I., Cognitive Science and the New Testament. A New Approach to Early Christian Research (Oxford: Oxfrod University Press 2017).

Czajkowski, M., Egzystencjalna lektura Biblii (Lublin: Redakcja Wydawnictw KUL 1993).

Delitzsch, F., System der biblischen Psychologie (Leipzig: Dörffling \& Francke 1855).

Drewermann, E., Tiefenpsychologie und Exegese (Olten: Walter 1985) I-II.

Drewermann, E., Strukturen des Bösen. I. Die jahwistische Urgeschichte in psychoanalytischer Sicht (Padeborn: Schöningh 1988).

Dymkowski, M., „O uniwersalności teorii psychologii społecznej”, Psychologia Społeczna 2 (2007) 249-261.

Ellens, J.H. - Rollins, W.G. (red.). Psychology and the Bible. A New Way to Read the Scriptures (Westport, CT: Praeger 1999-2004) I-IV.

Elliott, J.H., Conflict, Community, and Honor. 1 Peter in Social-Scientific Perspective (Eugene, OR: Wipf \& Stock 2007).

Elliott, J.H., „From Social Description to Social-Scientific Criticism. The History of a Society of Biblical Literature Section 1973-2003", Biblical Theology Bulletin 38 (2008) 26-36.

Esler, P.F., The First Christians in their Social Worlds. Social-scientific Approaches to New Testament Interpretation (New York - London: Routledge 1994).

Esler, P.F., „Intergroup Conflict and Matthew 23: Towards Responsible Historical Interpretation of a Challenging Text", Biblical Theology Bulletin 45/1 (2015) 38-59.

Fletcher, M.S., The Psychology of the New Testament (New York: Hodder \& Stoughton 1912).

Freud, S., „Czynności natrętne a praktyki religijne”, S. Freud, Charakter i erotyka (Warszawa: Wydawnictwo KR 1996) 5-14.

Freud, Z., „Totem i Tabu”, Z. Freud, Człowiek, religia, kultura (Warszawa: Książka i Wiedza 1967) $25-146$.

Freud, Z., „Przyszłość pewnego złudzenia”, Z. Freud, Człowiek, religia, kultura (Warszawa: Książka i Wiedza 1967) 147-199.

Gray, K. - Young, L. - Waytz, A., „Mind Perception Is the Essence of Morality”, Psychological Inquiry 23/2 (2012) 101-124. 
Grün, A., Bilder von Seelsorge. Biblische Modelle einer therapeutischen Pastoral (Mainz: Grünewald 1991).

Hakola, R., „Social Identities and Group Phenomena in Second Temple Judaism”, Explaining Christian Origins and Early Judaism. Contributions from Cognitive and Social Science (red. P. Luomanen - I. Pyysiäinen - R. Uro) (Leiden: Brill 2007) 259-276.

Hakola, R., „Social Identity and a Stereotype in the Making: The Pharisees as Hypocrites in Matt 23”, Identity Formation in the New Testament (red. B. Holmberg - M. Winnige) (Wissenschaftliche Untersuchungen zum Neuen Testament 227; Tübingen: Mohr Siebeck 2008) 121-139.

Hakola, R., „The Burden of Ambiguity: Nicodemus and the Social Identity of the Johannine Christians", New Testament Studies 55 (2009) 438-455.

Heyden, H., ,Religious Cognition as Social Cognition”, Studia Religiologica 48/4 (2015) 301-312.

Hofstede, G., Culture's Consequences. Comparing Values, Behaviors, Institutions and Organizations across Nations (Thousand Oakes, CA: Sage 2001).

Holmberg, B. - Winninge, M. (eds.), Identity formation in the New Testament (Tübingen: Mohr Siebeck 2008).

Horrell, D.G., „Social Sciences Studying Formative Christian Phenomena: A Creative Movement”, Handbook of Early Christianity. Social Science Approaches (red. A. Blasi - J. Duhaime P.-A. Turcotte) (Walnut Creek, CA: AltaMira Press 2002) 3-28.

Jung, C.G., „Odpowiedź Hiobowi”, C.G. Jung, Psychologia a religia Wschodu i Zachodu (tt. R. Reszke) (Warszawa: Wydawnictwo KR 2005) 553-758.

Jung, C.G., Archetypy i symbole. Pisma wybrane (tt. J. Prokopiuk) (Warszawa: Czytelnik 1976).

Jung, C.G., Archetypy i nieświadomość zbiorowa (tł. R. Reszke) (Warszawa: Wydawnictwo KR 2011). Ketola, K., „A Cognitive Approach to Ritual Systems in First-Century Judaism”, Explaining Early Judaism and Christianity. Contributions from Cognitive and Social Science (red. P. LuomanenI. Pyysiainen - R. Uro) (Leiden: Brill 2007) 95-114.

Kille, D.A., „Unconsciously Poisoning the Roots: Psychological Dynamics of the Bible in Jewish/ Christian Conflict", Pastoral Psychology 53/4 (2015) 291-301.

Lamp, J.S., „Is Paul Anti-Jewish? Testament of Levi 6 in the Interpretation of 1 Thessalonians 2:13-16", The Catholic Biblical Quarterly 65/3 (2003) 408-427.

László, J. et al., „Narrative Language as an Expression of Individual and Group Identity: The Narrative Categorical Content Analysis", Sage Open 3 (2013) 1-12.

Liu, J.H. - László, J., „A Narrative Theory of History and Identity: Social Identity, Social Representations, Society and the Individual", Social Representations and Identity. Content, Process, and Power (red. G. Moloney - I. Walker), (London: Palgrave Macmillan 2007) 85-107.

Lohfink, G. - Pesch, R., Tiefenpsychologie und keine Exegese. Eine Auseinandersetzung mit Eugen Drewermann (Stuttgart: Katholisches Bibelwerk 1987).

Luomanen, P. - Pyysiainen, I. - Uro, R. (red.), Explaining Early Judaism and Christianity. Contributions from Cognitive and Social Science (Leiden: Brill 2007).

Macpherson, D., „The Politics of Preaching the Promised Land for the Canaanites”, Political Theology 10/1 (2009) 71-84.

Markus, H.R. - Kitayama, Sh., „Culture and the Self: Implications for Cognition, Emotion, and Motivation", Psychological Review 98/2 (1991) 224-253. 
Martin, L., „The Promise of Cognitive Science for the Study of Early Christianity”, Explaining Early Judaism and Christianity. Contributions from Cognitive and Social Science (red. P. LuomanenI. Pyysiainen - R. Uro) (Leiden: BRILL 2007) 35-56.

Matsumoto, D.R. - Juang, L., Psychologia międzykulturowa (Gdańsk: GWP 2007).

Miller, D.L., Jung and the Interpretation of the Bible (New York: Continuum 1997).

Nebreda, R., Christ Identity. A Social-Scientific Reading of Philippians 2,5-11 (Göttingen: Vandenhoeck \& Ruprecht 2011).

Nisbett, R., Geografia myślenia (Sopot: Smak Słowa 2009).

Pilch, J. (red.), Social Scientific Models for Interpreting the Bible. Essays by the Context Group in Honor of Bruce J. Malina (Biblical Interpretation Series 53; Leiden: Brill 2001).

Rollins, W.G., Soul and Psyche. The Bible in Psychological Perspective (Minneapolis, MN: Fortress 1999).

Rollins, W.G. - Kille, A.D. (red.), Psychological Insight into the Bible(Grand Rapids, MI - Cambridge: Eerdmanns 2007).

Roos, M., F., Fundamenta psychologiae ex sacra Scriptura sic collecta (Tübingen: Fuessi 1769).

Rossano, M.J., „The Religious Mind and the Evolution of Religion”, Review of General Psychology 10/4 (2006) 346-364.

Rubinkiewicz, R. (red.), Interpretacja Biblii w Kościele. Dokument Papieskiej Komisji Biblijnej z komentarzem biblistów polskich (Rozprawy i Studia Biblijne 4; Warszawa: Vocatio 1999).

Schwartz, S.H., „A Theory of Cultural Values and Some Implications for Work”, Applied Psychology 48/1 (1999) 23-47.

Schwartz, S.H. - Sagiv, L., „Identifying Cultures Specifics in the Content and Structure of Values”, Journal of Cross-Cultural Psychology 26/1 (1995) 92-116.

Spiegel, Y. (red.), Psychoanalytische Interpretationen biblischer Texte (München: Kaiser 1972).

Suchy, J., „Podejście psychologiczne i psychoanalityczne w egzegezie biblijnej”, Collectanea Theologica 66/1 (1996) 55-64.

Tajfel, H., Social Identity and Intergroup Relations (Cambridge: Cambridge University Press 1982).

Tajfel, H., „Stereotypy społeczne i grupy społeczne”, Studia Psychologiczne 20/2 (1982) 5-25.

Tajfel, H. - Billig, M., ,Social Categorization and Similarity in Intergroup Behavior”, European Journal of Social Psychology 3 (1973) 27-52.

Tajfel, H. - Turner, J.C, „The Social Identity Theory of Intergroup Behavior”, Psychology of Intergroup Relation (red. W. Austin - S. Worchel) (Monterey, CA: Brooks - Cole 1986) 33-47.

Theissen, G., Psychologische Aspekte der paulinischen Theologie (Göttingen: Vandenhoeck \& Ruprecht 1983).

Theissen, G., Erleben und Verhalten der ersten Christen. Eine Psychologie des Urchristentums (Gütersloh: Gütersloher Verlagshaus 2007).

Theissen, G. - von Gemünden, P. (red.), Erkennen und Erleben. Beiträge zur psychologischen Erforschung des frühen Christentums (Gütersloh: Gütersloher Verlagshaus 2007).

Tremlin, T., Minds and Gods. The Cognitive Foundations of Religion (Oxford: Oxford University Press 2010).

Triandis, H.C., Individualism and Collectivism (Boulder, CO: Westview Press 1995).

Turner, J.C., Rediscovering the Social Group: Self-Categorization Theory (New York: Blackwell 1987).

Turner, J.C., „Towards a Cognitive Redefinition of the Social Group”, Social Identity and Intergroup Relations (red. H. Tajfel) (Cambridge: Cambridge University Press 1992) 15-39. 
Wierzbicka, A., Stowa-klucze. Różne języki - różne kultury (Warszawa: Wydawnictwo Uniwersytetu Warszawskiego 2007).

Wolff, H., Jesus der Mann. Die Gestalt Jesu in tiefenpsychologischer Sicht (Stuttgart: Radius 1984). 
